\title{
Segregation analysis of microsatellite (SSR) markers in sugarcane polyploids
}

\author{
X. Lu' ${ }^{1,2 *}$, H. Zhou ${ }^{1,3 *}$, Y.-B. Pan ${ }^{1 *}$, C.Y. Chen ${ }^{4}$, J.R. Zhu' ${ }^{1,2}$, P.H. Chen ${ }^{5}$, Y.-R. Li ${ }^{3}$, \\ Q. $\mathrm{Cai}^{2}$ and R.K. Chen \\ 1Sugarcane Research Laboratory, Agricultural Research Service, \\ United States Department of Agriculture, Houma, LA, USA \\ ${ }^{2}$ Yunnan Key Laboratory of Sugarcane Genetic Improvement, \\ Sugarcane Research Institute, Yunnan Academy of Agricultural Sciences, \\ Kaiyuan, Yunnan, China \\ ${ }^{3}$ Laboratory of Sugarcane Biotechnology and Genetic Improvement (Guangxi), \\ Ministry of Agriculture and Sugarcane Research Institute, \\ Guangxi Academy of Agricultural Sciences, Nanning, Guangxi, China \\ ${ }^{4}$ Department of Crop, Soil and Environmental Sciences, Auburn University, \\ Auburn, AL, USA \\ ${ }^{5}$ Key Laboratory of Eco-Physiology \& Genetic Improvement for Sugarcane, \\ Ministry of Agriculture and Fujian Agriculture and Forestry University, \\ Fujian Normal University, Fuzhou, Fujian, China \\ ${ }^{*}$ These authors contributed equally to this study. \\ Corresponding author: Y.-B. Pan \\ E-mail: YongBao.Pan@ars.usda.gov
}

Genet. Mol. Res. 14 (4): 18384-18395 (2015)

Received August 16, 2015

Accepted October 1, 2015

Published December 23, 2015

DOI http://dx.doi.org/10.4238/2015.December.23.26

ABSTRACT. No information is available on segregation analysis of DNA markers involving both pollen and self-progeny. Therefore, we used capillary electrophoresis- and fluorescence-based DNA fingerprinting together with single pollen collection and polymerase chain reaction (PCR) to investigate simple sequence repeat (SSR) marker segregation among 964 single pollens and 288 self-progenies $\left(\mathrm{S}_{1}\right)$ of sugarcane cultivar LCP 85-384. Twenty SSR DNA fragments (alleles) were amplified by five polymorphic 
SSR markers. Only one non-parental SSR allele was observed in 2392 PCRs. SSR allele inheritance was in accordance with Mendelian laws of segregation and independent assortment. Highly significant correlation coefficients were found between frequencies of observed and expected genotypes in pollen and $S_{1}$ populations. Within the $S_{1}$ population, the most frequent genotype of each SSR marker was the parental genotype of the same marker. The number of genotypes was higher in pollen than $\mathrm{S}_{1}$ population. PIC values of the five SSR markers were greater in pollen than $S_{1}$ populations. Eleven of 20 SSR alleles (55\%) were segregated in accordance with Mendelian segregation ratios expected from pollen and $\mathrm{S}_{1}$ populations of a $2 n=10 x$ polyploid. Six of 20 SSR alleles were segregated in a 3:1 (presence:absence) ratio and were simplex markers. Four and one alleles were segregated in 77:4 and 143:1 ratios and considered duplex and triplex markers, respectively. Segregation ratios of remaining alleles were unexplainable. The results provide information about selection of crossing parents, estimation of seedling population optimal size, and promotion of efficient selection, which may be valuable for sugarcane breeders.

Key words: Saccharum spp. hybrids; Polyploidy; Microsatellite DNA marker; Pollen; Self-progeny

\section{INTRODUCTION}

Cultivated forms of sugarcane (Saccharum spp. hybrids, $2 n=100-130$ ) are heterozygous aneupolyploid derivatives of interspecific hybrids primarily involving Saccharum officinarum $L$. and S. spontaneum L., with contributions from S. barberi Jeswiet, S. sinense Roxb., and S. robustum Brandes and Jeswiet ex Grassl (Dillon et al., 2007). The complex genomic structure makes sugarcane a difficult subject for genetic research, particularly in classical studies. Due to the lack of knowledge on sugarcane classical genetics, sugarcane breeding is a long and not very efficient process. In addition, in non-tropical areas, sugarcane needs to be induced to flower. The miniscule and fragile flowers are perfect and often self-pollinate. Emasculation is either impractical or inefficient and the separation of hybrids obtained from self-pollination by visual inspection at an early seedling stage has not been possible yet. Molecular marker-assisted selection has been used in the breeding process of several crops (Collard and Mackill, 2008). Since the late 1980s, sugarcane breeders and geneticists have explored the use of several DNA markers to improve sugarcane breeding. These DNA markers include restriction fragment length polymorphism (RFLP), random amplified polymorphic DNA (RAPD), amplified fragment length polymorphism (AFLP), the 5S rRNA ITS marker, targeted region amplified polymorphism (TRAP), single nucleotide polymorphism (SNP), and microsatellites or simple sequence repeats (SSRs) (Pan, 2006).

SSR markers are short DNA fragments that contain various numbers of tandem repeat units of di-, tri-, tetra- or composite-nucleotide motifs (Edwards et al., 1991; Polymeropoulos et al., 1991). SSR markers are useful for the evaluation of genetic diversity and varietal identification because they are abundant, co-dominantly inherited, and highly reproducible (Cordeiro et al., 2000 , 2001). Toward the end of last century, the International Sugarcane Microsatellite Consortium (ISMC) developed 221 SSR markers based on the genomic DNA sequence of sugarcane cultivars 
Q124 (Australian) and R570 (French Reunion) (Cordeiro et al., 2000). These ISMC SSR markers were evaluated on five elite U.S. sugarcane clones and only 67 (30\%) produced robust PCR amplified products (Pan, 2006). Later, Singh et al. (2008) and Parida et al. (2009) developed 168 sugarcane SSR markers based on the EST and genomic sequences of elite Indian germplasm. One hundred and fifty-two of these Indian SSR markers were evaluated on LCP 85-384, an elite cultivar from Louisiana, and 110 (70\%) produced PCR products (Liu et al., 2011).

Since the beginning of the 21st century, SSR markers have been widely used to study the genetic diversity of Saccharum species and the genetic relationships among them and related genera (Cordeiro et al., 2003; Cai et al., 2005; Chen et al., 2009; Banumathi et al., 2010; Singh et al., 2010; Ukoskit et al., 2012). SSR markers have also been important in sugarcane genetic mapping studies (Aitken et al., 2005; Edme et al., 2006; Suman et al., 2011). To improve the efficiency of sugarcane breeding, some of the transferable SSR markers have been successfully used for molecular genotyping of sugarcane germplasm (Pan et al., 2003, 2007), identification of hybrid progeny from interspecific crosses (Pan et al., 2006), paternity analysis of polycross progeny (Tew and Pan, 2010), and construction of a sugarcane molecular identity database (Pan, 2010).

By comparing SSR fingerprints among progeny and parent clones, sugarcane breeders were able to classify three groups of cross progeny (Tew and Pan, 2005; Pan et al., 2007). The hybrid group has at least one male-specific allele, but no non-parental alleles, the off-type group has non-parental alleles, and the self/hybrid group has only alleles from female parents (Tew and Pan, 2005; Pan et al., 2007). If alleles from the self/hybrid group are also shared with male parents, the progeny may be a hybrid, although the probability of this happening is unknown. Therefore, knowledge on the inheritance of SSR DNA markers in sugarcane is needed to address this problem. Parental reproductive cells (gametes) undergo meiosis to produce gametes, which contribute, after fertilization, to the nuclear genomes of the progeny. Female gametes (eggs) are inaccessible but male gametes (pollen grains) are abundant and easily accessible. If the genotypes of pollen grains are known, then the genotypes of the eggs are also known. Chen et al. (2008) were able to collect individual sugarcane pollen grains and conduct RAPD PCR on each single grain. These authors demonstrated that single pollen grains of sugarcane and several other plant species could be collected using a pair of fine-tipped forceps under magnification. Single pollen grains were lysed in a hot alkaline detergent solution and neutralized with an equimolar TE buffer. The resulting solution produced good PCR products with both RAPD and $5 S$ rRNA-ITS markers. The success of this earlier study has prompted us to genotype single sugarcane pollen grains with SSR DNA markers. The objective of the present study is to investigate the segregation pattern of SSR alleles among pollen grains and selfed progeny in sugarcane populations.

\section{MATERIAL AND METHODS}

\section{Plant materials}

In early October 2010, non-dehisced florets were collected from a flower of LCP 85-384 (Milligan et al., 1994), a superior sugarcane cultivar that occupied $91 \%$ of the Louisiana sugarcane acreage in 2004 , and stored at $4^{\circ} \mathrm{C}$. Young leaf tissue from the same plant was also collected and total nucleic acids were extracted according to Pan et al. (2000). The self-progeny mapping population $\left(\mathrm{S}_{1}\right)$ of LCP 85-384 was also included in this study. Because sugarcane cultivars such as LCP 85-384 are highly heterozygous, $\mathrm{S}_{1}$ progeny from selfing of a sugarcane clone were also 
considered as a pseudo $\mathrm{F}_{2}$ population. Although more than $1000 \mathrm{~S}_{1}$ progenies have been produced by selfing, only 300 were included in a genetic mapping study (Suman et al., 2011). The LCP 85$384 \mathrm{~S}_{1}$ progeny mapping population has been maintained since 2005.

\section{SSR markers}

Two SSR markers (SMC336BS and SMC1604SA) from the International Sugarcane Microsatellite Consortium (ISMC) (Cordeiro et al., 2000; Pan, 2006) and three (SCM7, UGSM10, and UGSM97) from the Indian Agricultural Research Institute (IARI) (Singh et al., 2008; Parida et al., 2009) were used in this study (Table 1). These SSR markers produce distinctive robust fingerprints without non-specific fragments such as stutters or dinosaur tails (Pan et al., 2003).

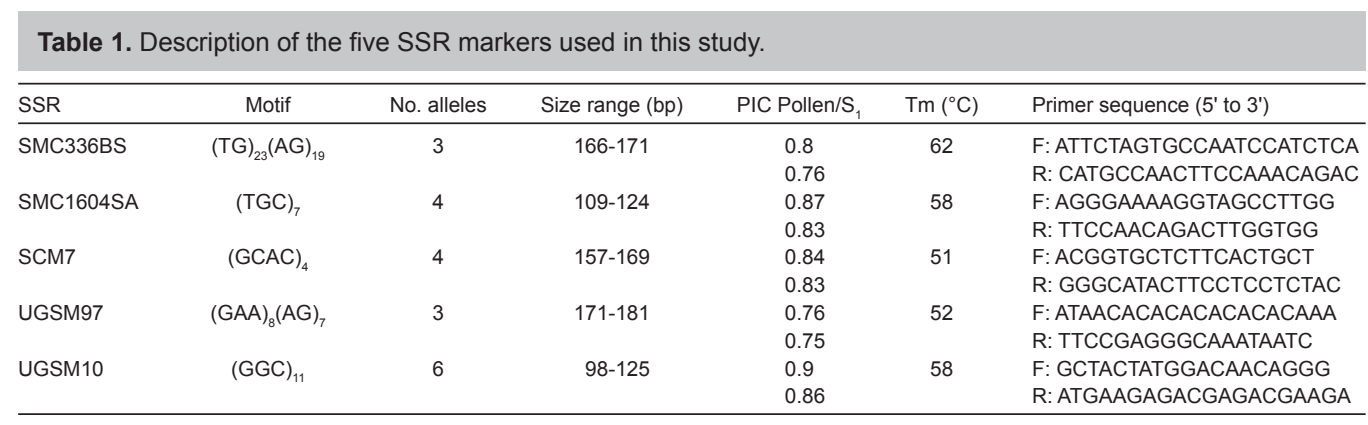

\section{$S_{1}$ DNA extraction and PCR}

Young and actively growing leaves were collected from greenhouse pot plants, placed on ice, and eventually stored in a refrigerator until DNA extraction. Genomic DNA was extracted using both the Plant DNeasy Mini Kit (Qiagen, Valencia, CA) following the manufacturer protocol and the CTAB procedure. Concentrations of extracted DNA were estimated with the NanoDrop 1000 spectrophotometer (NanoDrop, Bethesda, MD) at $260 \mathrm{~nm}$ wavelength absorbance and the DNA was stored at $-20^{\circ} \mathrm{C}$. The quality of the DNA was checked by measuring the ratio between 260 and $280 \mathrm{~nm}$.

The Hamilton's Microlab Star Liquid Handling Station (Hamilton Company, Reno, NV) was used to prepare 384-well PCR plates each well containing $5 \mu \mathrm{L} \mathrm{PCR} \mathrm{mixture.} \mathrm{The} \mathrm{mixture} \mathrm{consisted}$ of $0.25 \mu \mathrm{L}$ DNA sample, $0.5 \mu \mathrm{L} 10 \mathrm{X}$ buffer, $0.3 \mu \mathrm{L} 25 \mathrm{mM} \mathrm{MgCl}_{2}, 0.1 \mu \mathrm{L} 10 \mathrm{mM}$ dNTPs, $0.41 \mu \mathrm{L}$ each $3 \mathrm{pM}$ forward and reverse primers, $0.5 \mu \mathrm{L} 10 \mathrm{mg} / \mathrm{ml}$ BSA-V, $0.5 \mu \mathrm{L} 100 \mathrm{mg} / \mathrm{ml}$ PVP-40, $0.025 \mu \mathrm{L} 5$ $\mathrm{U} / \mu \mathrm{L}$ Taq DNA polymerase, and 2.0 $\mu \mathrm{L}$ PCR-grade water. PCR amplification was conducted on a DNA Engine Tetra equipped with four 384-well Alpha blocks with heated lids (Bio-Rad Laboratories, Hercules, CA) with the following thermal cycling program: $95^{\circ} \mathrm{C}$ for $15 \mathrm{~min} ; 40$ cycles of $94^{\circ} \mathrm{C}$ for $15 \mathrm{~s}$, annealing for $15 \mathrm{~s}$, and $72^{\circ} \mathrm{C}$ for $1 \mathrm{~min}$; a final extension at $72^{\circ} \mathrm{C}$ for $10 \mathrm{~min}$; and a final hold temperature of $4^{\circ} \mathrm{C}$. The annealing temperature varied according to the SSR primer pair.

\section{Single pollen collection, lysis, and PCR}

The single pollen collection and PCR protocol of Chen et al. (2008) was followed with some modifications. Briefly, three non-dehisced anthers were added to a $0.5 \mathrm{ml}$ microfuge tube containing $50 \mu \mathrm{L}$ staining solution (30 mM sucrose solution with $0.7 \mathrm{mM}$ aniline blue diammonium 
salt). The anthers were broken up using a pair of forceps, and debris of anther sacs was removed from the tube. Two microliters of pollen suspension solution was spotted on a nylon membrane, which was placed under a Keyence Digital Microscope VHX-600E (Keyence Corporation, Osaka, Japan). Under a 150X magnification, single stained pollen grains were picked up using a pair of fine-tipped forceps (FST DUMONT No. 5, Medical Biology, Switzerland) and transferred individually into $0.2 \mathrm{~mL}$ PCR tubes (USA Scientific, Ocala, FL, USA) preloaded with $1 \mu \mathrm{L}$ freshly prepared lysis solution (10\% Tween-20, $0.1 \mathrm{M} \mathrm{NaOH})$.

After adding $5 \mu \mathrm{L}$ mineral oil (Sigma, St. Louis, MO, USA), PCR tubes were spun for $1 \mathrm{~min}$ at $6000 \mathrm{rpm}$ in a desktop PHOENIX QUIKSPIN Minifuge (Phoenix Research Products, Candler, $\mathrm{NC}$, USA) (Figure 1). Tubes were then heated to $95^{\circ} \mathrm{C}$ for $17 \mathrm{~min}$ and $30 \mathrm{~s}$ and placed on ice to cool down. After a brief spin, $1 \mu \mathrm{L}$ neutralization buffer $(0.1 \mathrm{M}$ Tris-HCl, $2 \mathrm{mM}$ EDTA) was added to each well. After a $1 \mathrm{~min}$ spin, $18 \mu \mathrm{L}$ PCR buffer $\left(2 \mu \mathrm{L} 10 \mathrm{X}\right.$ reaction buffer, $1.2 \mu \mathrm{L} 25 \mathrm{mM} \mathrm{MgCl}_{2}, 0.4$ $\mu \mathrm{L} 10 \mathrm{mM}$ dNTPs, $0.5 \mu \mathrm{L}$ each $10 \mu \mathrm{M}$ forward and reverse primers, $2 \mu \mathrm{L} 10 \mathrm{mg} / \mathrm{mL}$ BSA, $0.2 \mu \mathrm{L} 5$ $\mathrm{U} / \mu \mathrm{L}$ Taq DNA polymerase, and $11.2 \mu \mathrm{L}$ PCR-grade water) was added to each tube.

The pollen SSR-PCR thermal cycling program was as follows: $95^{\circ} \mathrm{C}$ for $15 \mathrm{~min} ; 40$ cycles of $94^{\circ} \mathrm{C}$ for $55 \mathrm{~s}$, annealing for $20 \mathrm{~s}$, and $72^{\circ} \mathrm{C}$ for $40 \mathrm{~s}$; and a final extension at $72^{\circ} \mathrm{C}$ for $10 \mathrm{~min}$. The annealing temperature varied according to the SSR primer pair used. PCR amplifications were conducted on a GeneAmp PCR System 9700 (Applied Biosystems, Inc., Foster City, CA, USA). Next, $5 \mu \mathrm{L}$ PCR product was separated by electrophoresis on $1.5 \%$ agarose gels containing ethidium bromide $(0.5 \mu \mathrm{g} / \mathrm{mL})$ in $0.5 X$ TBE buffer. Gel images were captured on a Gel Logic 200 Imaging System (Eastman Kodak, Rochester, NY). For pollen PCR samples that failed to show any SSR product, $2 \mu \mathrm{L}$ from the remaining PCR product was subjected to PI [5' TGG GAA GTC CT(C/T) GTG TTG CA] and PII [5' (T/G)T(A/C) G(T/C)G CTG GTA TGA TCG CA]-primed PCR amplification (Cox et al., 1992) after mixing with $18 \mu \mathrm{L}$ reaction buffer as described above. The PI/PII PCR thermal cycling program was as follows: $95^{\circ} \mathrm{C}$ for $15 \mathrm{~min} ; 40$ cycles of $94^{\circ} \mathrm{C}$ for 55 $\mathrm{s}, 60^{\circ} \mathrm{C}$ for $10 \mathrm{~s}$, and $72^{\circ} \mathrm{C}$ for $40 \mathrm{~s}$; and a final extension at $72^{\circ} \mathrm{C}$ for $10 \mathrm{~min}$. Gel separation and visualization of PI/PII PCR products were conducted as described above.

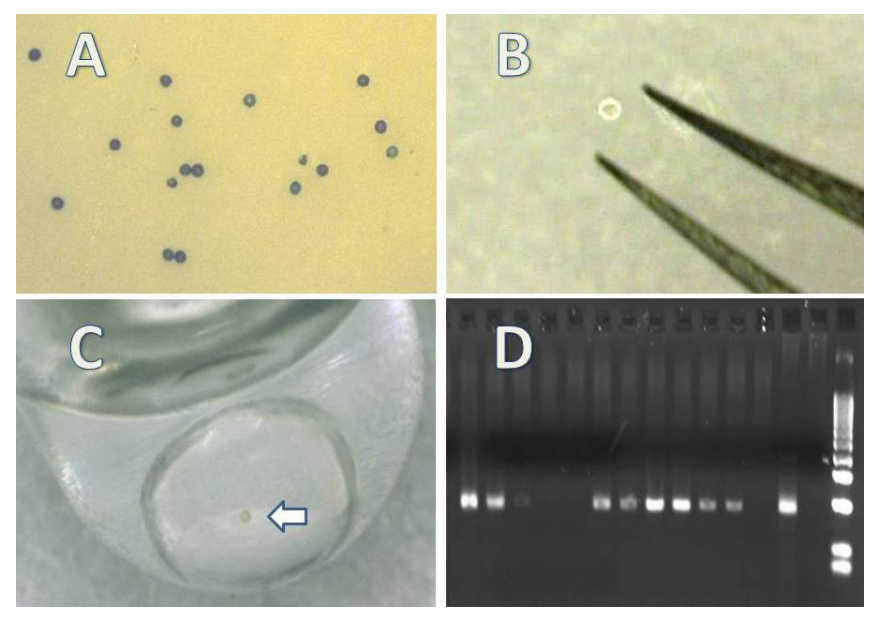

Figure 1. Single pollen grain collection and PCR in sugarcane. A. Stained individual sugarcane pollen grains on nylon membrane; B. picking single pollen grains with a pair of DUMONT forceps (N. 11254-20); C. a single pollen grain (arrow) inside a PCR tube; and D. single SSR-PCR products on agarose gel (DNA size markers are shown in the right lane). 


\section{Capillary electrophoresis (CE)-based fragment analysis}

The remaining pollen SSR-PCR products in individual PCR tubes were manually transferred to individual wells of 96-well microplates. A Hamilton's Microlab Star Liquid Handling Station with a 96 probe head and eight independent pipette channels (Hamilton Company, Reno, NV) was used to consolidate pollen SSR-PCR samples from four 96-well plates into a single 384-well plate. The robot was used again to prepare 384-well CE sample plates by first diluting the amplified SSR DNA fragments and then dispensing $1 \mu \mathrm{L}$ diluted SSR products and $9 \mu \mathrm{L}$ Hi-Dye formamide solution premixed with Rox ${ }^{\mathrm{TM}} 500$ size standards in each well following the manufacturer protocol (Applied Biosystems, Inc., Foster City, CA). CE sample plates were run on an ABI3730 Genetic Analyzer (Applied Biosystems, Inc., Foster City, CA).

\section{Marker scoring}

Individual GeneScan files were analyzed with both GeneMapper ${ }^{\mathrm{TM}}$ (Applied Biosystems, Inc., Foster City, CA) and GeneMarker ${ }^{\mathrm{TM}}$ (SoftGenetics, LLC, State College, PA) software. The presence of an SSR allele was scored as ' 1 ' and its absence as '0'. SSR markers were coded by name and identity number according to the Sugarcane Microsatellite Consortium (Cordeiro et al., 2000) and the Indian Agricultural Research Institute (IARI) (Singh et al., 2008; Parida et al., 2009) along with the allele size as suffix. Several types of irregular peaks including "stutters", "pullups", "dinosaur tails", and "minus-A peaks" were not scored following Pan (2006). Polymorphism information content (PIC) values were computed using the formula of Milbourne et al. (1997):

$$
\mathrm{PIC}=1-\sum_{\mathrm{j}=1}^{\mathrm{n}} \mathrm{Pij}^{2}
$$

where $P i j$ is the frequency of the $j$ th allele for marker $i$ and summation extends over $n$ alleles.

\section{Segregation analyses}

Several segregation ratios were expected from $\mathrm{S}_{1}$ and pollen populations. Marker dose was estimated based on the expected segregation ratios from pollen and $\mathrm{S}_{1}$ progeny populations. Selected markers were tested for the expected Mendelian ratio of 1:1, 7:2, and 11:1 (pollen population), and 3:1, 77:4 and, 143:1 ( $\mathrm{S}_{1}$ population) for simplex, duplex, and triplex markers, respectively, using the chi-square test at a significance level of $5 \%$ (Table 2 ).

Table 2. Theoretical segregation ratio between simplex/simplex, duplex/duplex and triplex/triplex markers among pollen grains (gamete) and $\mathrm{S}_{1}$ progeny populations.

\begin{tabular}{lccc}
\hline & Single dose (coupling) & Double dose (coupling) & Triple dose (coupling) \\
\hline Autodecaploid $(2 n=10 x)^{*}$ & Aaaaaaaaaa & AAaaaaaaaa & AAAaaaaaaa \\
Pollen $($ gamete) & $1: 1$ & $7: 2$ & $11: 1$ \\
S $_{1}$ progeny $^{*}$ & $3: 1$ & $77: 4$ & $143: 1$ \\
\hline
\end{tabular}

${ }^{*}$ Adapted from Ripol et al. (1999) and Suman et al. (2011). 


\section{RESULTS}

Five SSR markers primed the amplification of 20 alleles from both pollen and $\mathrm{S}_{1}$ progeny of LCP 85-384. Allele size ranged from 98 to $181 \mathrm{bp}$. Of these 20 alleles, three $(166,169$, and $171 \mathrm{bp})$ were from SMC336BS, four (109, 112, 118, and $124 \mathrm{bp})$ from SMC1604SA, four (157, 161, 165, and $169 \mathrm{bp})$ from SCM7, three $(171,176$, and $181 \mathrm{bp})$ from UGSM97, and six $(98,102,109,117,208$, and $125 \mathrm{bp}$ ) from UGSM10 (Table 1). The number of single pollen grains used for amplifying alleles of SMC336BS, SMC1604SA, SCM7, UGSM97, and GSM10 were 196, 224, 227, 109, and 188, respectively. The numbers of $\mathrm{S}_{1}$ progenies used for allele amplification of SMC336BS, SMC1604SA, SCM7, UGSM97, and GSM10 were 286, 288, 280, 286, and 288, respectively (Table 3). Interestingly, only one non-parental SSR allele (SMC366BS_164) was observed from a single SMC336BS-primed PCR amplification out of 2392 PCR amplifications conducted in this study. All five SSR markers exhibited relatively high PIC values in both pollen (0.76-0.90) and $S_{1}$ populations (0.75-0.86) (Table 1).

In total, eight pollen gamete genotypes were observed for SMC336BS, 16 for SMC1604SA, 12 for SCM7, six for UGSM97, and 43 for UGSM10, which accounted for 100, 100, 75, 75, and $67 \%$ of the theoretically expected number of genotypes, respectively. However, with the exception of SMC336BS, fewer genotypes were detected in the $\mathrm{S}_{1}$ population: 11 (69\%) for SMC1604SA, 10 $(63 \%)$ for SCM7, four (50\%) for UGSM97 and 17 (27\%) for UGSM10 (Table 3). For SMC336BS, eight genotypes were also observed in the $S_{1}$ population, which accounted for $100 \%$ of the theoretically expected number of genotypes. In contrast, the marker UGSM10 produced the lowest ratio between observed and theoretically expected genotypes both in pollen (67\%) and $\mathrm{S}_{1}(27 \%)$ populations (Table 3). The relative frequency of each observed genotype among pollen populations ranged from 2.04 to $26.02 \%$ for SMC336BS, 1.34 to $17.41 \%$ for SMC1604SA, 0.44 to $34.36 \%$ for SCM7, 2.75 to $55.96 \%$ for UGSM97, and 0.48 to $12.50 \%$ for UGSM10 (data not shown). The relative frequency of each observed genotype in the $S_{1}$ population ranged from 0.35 to $49.65 \%$ for SMC336BS, 0.35 to $35.76 \%$ for SMC1604SA, 0.36 to $35.71 \%$ for SCM7, 3.15 to $54.20 \%$ for UGSM97, and 0.35 to $44.10 \%$ for UGSM10 (data not shown).

Overall, highly significant correlation coefficients $\left(R^{2}\right)$ were found between observed and theoretically expected genotypes (Table 3). All $R^{2}$ values for the $S_{1}$ population were greater than 0.95. Among pollen populations, the lowest $R^{2}$ value was 0.87 for the genotype of the marker SMC1604SA and the highest was 0.99 for the UGSM97 marker. It is interesting to notice that the most frequent genotype among the $S_{1}$ population was also the LCP 85-384 genotype of that marker. Furthermore, pollen populations showed equal or higher number of genotypes than the $\mathrm{S}_{1}$ population.

\begin{tabular}{|c|c|c|c|c|c|c|}
\hline \multirow[t]{2}{*}{ SSR primer } & \multirow[t]{2}{*}{ Population } & \multirow[t]{2}{*}{ No. Samples } & \multirow[t]{2}{*}{ No. alleles } & \multicolumn{2}{|c|}{ No. of genotypes } & \multirow[t]{2}{*}{$R^{2}$} \\
\hline & & & & Observed (\%) & Expected & \\
\hline \multirow{2}{*}{ SMC336BS } & Pollen & $196\left(10^{\mathrm{a}}\right)$ & 3 & $8(100 \%)$ & 8 & $0.9650^{\star *}$ \\
\hline & S1 & 286 & 3 & $8(100 \%)$ & 8 & $0.9855^{\star *}$ \\
\hline \multirow[t]{2}{*}{ SMC1604SA } & Pollen & $224\left(5^{\mathrm{a}}\right)$ & 4 & $16(100 \%)$ & 16 & $0.8711^{\text {** }}$ \\
\hline & $\mathrm{s} 1$ & 288 & 4 & $11(68.8 \%)$ & 16 & $0.9528^{* *}$ \\
\hline \multirow[t]{2}{*}{ SCM7 } & Pollen & $227\left(20^{\mathrm{a}}\right)$ & 4 & $12(75.0 \%)$ & 16 & $0.9836^{\star *}$ \\
\hline & S1 & 280 & 4 & $10(62.5 \%)$ & 16 & $0.9959^{* *}$ \\
\hline \multirow[t]{2}{*}{ UGSM97 } & Pollen & $109\left(6^{a}\right)$ & 3 & $6(75.0 \%)$ & 8 & $0.9932^{* *}$ \\
\hline & S1 & 286 & 3 & $4(50.0 \%)$ & 8 & $0.9898^{* *}$ \\
\hline \multirow[t]{2}{*}{ UGSM10 } & Pollen & $208\left(5^{\mathrm{a}}\right)$ & 6 & $43(67.2 \%)$ & 64 & $0.8818^{\star *}$ \\
\hline & S1 & 288 & 6 & $17(26.6 \%)$ & 64 & $0.9985^{\star *}$ \\
\hline
\end{tabular}

aNumber of single pollen grains that did not produce any SSR product but showed positive PI/PII-primed PCR results. **Significant at 0.01 level. 


\section{Segregation of SSR alleles}

Based on the expected Mendelian segregation ratio of 1:1 (simplex), 7:2 (duplex), and 11:1 (triplex) in pollen populations, only four (UGSM10_121, SMC336BS_166, SMC1604SA_109, and SMC1604SA_118) out of 20 SSR alleles were segregated in a 1:1 (presence:absence) ratio and were, therefore, simplex markers. Six other SSR alleles (UGSM10_117, UGSM10_125, UGSM97_176, UGSM97_181, SMC336BS_169, and SMC1604SA_112) were classified as either duplex or triplex markers. The allele SMC1604SA_124 was segregated in a ratio of 2:7 (Table 4).

\begin{tabular}{|c|c|c|c|c|c|c|c|c|c|c|}
\hline Alleles & Observed ratio & $\begin{array}{l}\text { Single dose } \\
\quad(1: 1)\end{array}$ & $\mathrm{X}^{2}$ & $P$ value & $\begin{array}{l}\text { Double dose } \\
(7: 2) \text { or }(2: 7)\end{array}$ & $X^{2}$ & $P$ value & $\begin{array}{c}\text { Triple dose } \\
(11: 3) \text { or }(3: 11)\end{array}$ & $X^{2}$ & $P$ value \\
\hline UGSM10_117 & $151: 37$ & - & - & - & $146: 42$ & 0.56 & 0.453 & $147: 40$ & 0.25 & 0.62 \\
\hline UGSM10_121 & $104: 84$ & $94: 94$ & 1.92 & 0.166 & - & - & - & - & - & - \\
\hline UGSM10_125 & $41: 147$ & - & - & - & $42: 146$ & 0 & 0.961 & $40: 147$ & 0 & 0.97 \\
\hline UGSM97_176 & $22: 73$ & - & - & - & $21: 74$ & 0.01 & 0.923 & $20: 75$ & 0.08 & 0.776 \\
\hline UGSM97_181 & 19:76 & - & - & - & $21: 74$ & 0.16 & 0.691 & $20: 75$ & 0.05 & 0.083 \\
\hline SMC336BS_166 & $106: 82$ & 94:94 & 2.81 & 0.09 & - & - & - & - & - & - \\
\hline SMC336BS_169 & $156: 32$ & - & - & - & $146: 42$ & 2.65 & 0.104 & $148: 40$ & 1.92 & 0.166 \\
\hline SMC1604SA_109 & $96: 91$ & $93.5: 93.5$ & 0.09 & 0.77 & - & - & - & - & - & - \\
\hline SMC1604SA_112 & $140: 47$ & - & - & - & $145: 42$ & 0.76 & 0.385 & $147: 40$ & 1.31 & 0.252 \\
\hline SMC1604SA_118 & $98: 89$ & $93.5: 93.5$ & 0.34 & 0.559 & - & - & - & - & - & - \\
\hline SMC1604SA 124 & $53: 134$ & - & - & - & $42: 140$ & 3.7 & 0.054 & - & - & - \\
\hline
\end{tabular}

Based on the expected Mendelian segregation ratio of 3:1 (simplex), 77:4 (duplex), and 143:1 (triplex) in the $S_{1}$ population, six (UGSM10_125, UGSM97_176, UGSM97_181, SMC336BS_166, SMC7_157, and SMC7_161) out of 20 SSR alleles were segregated in a ratio of 3:1 and considered simplex markers. Four other alleles (UGSM10_102, UGSM10_121, SMC336BS_169, and SMC1604SA_112) were segregated in 77:4 ratio and were classified as duplex markers. One allele (SMC7_165) was segregated at a ratio of 143:1 and was considered a triplex marker (Table 5).

\begin{tabular}{|c|c|c|c|c|c|c|c|c|c|c|}
\hline SSR alleles & Observed ratio & $\begin{array}{l}\text { Single dose } \\
\quad(3: 1)\end{array}$ & $x^{2}$ & $P$ value & $\begin{array}{c}\text { Double dose } \\
(77: 4)\end{array}$ & $\mathrm{X}^{2}$ & $P$ value & $\begin{array}{c}\text { Triple dose } \\
(143: 1)\end{array}$ & $x^{2}$ & $P$ value \\
\hline UGSM10_102 & $273: 15$ & - & - & - & $274: 14$ & 0.006 & 0.939 & - & - & - \\
\hline UGSM10_121 & $267: 21$ & - & - & - & $274: 14$ & 2.918 & 0.088 & - & - & - \\
\hline UGSM10_125 & $213: 75$ & $216: 64$ & 1.48 & 0.224 & - & - & - & - & - & - \\
\hline UGSM97_176 & $210: 76$ & $214.5: 71.5$ & 0.298 & 0.585 & - & - & - & - & - & - \\
\hline UGSM97_181 & $222: 64$ & $214.5: 71.5$ & 0.914 & 0.339 & - & - & - & - & - & - \\
\hline SMC336BS_166 & $207: 81$ & $216: 72$ & 1.338 & 0.247 & - & - & - & - & - & - \\
\hline SMC336BS_169 & $276: 12$ & - & - & - & $274: 14$ & 0.219 & 0.64 & - & - & - \\
\hline SMC1604SA_112 & $269: 19$ & - & - & - & $274: 14$ & 1.355 & 0.244 & - & - & - \\
\hline SMC7_157 & $204: 76$ & $210: 70$ & 0.576 & 0.448 & - & - & - & - & - & - \\
\hline SMC7_161 & $207: 73$ & $210: 70$ & 0.119 & 0.73 & - & - & - & - & - & - \\
\hline SMC7_165 & $278: 2$ & - & - & - & - & - & - & 278.1:1.9 & 0.004 & 0.968 \\
\hline
\end{tabular}




\section{DISCUSSION}

Chen et al. (2008) were the first authors to use a high throughput procedure for single pollen grain collection. In the present study, the same protocol was followed with some modifications. First, pollen was collected under a KEYENCE Digital Microscope System (Model VHX-600E) with 150X magnification. Second, a nylon membrane was used to hold 2-3 $\mu \mathrm{L}$ pollen suspension. Because the nylon membrane easily absorbed the liquid, single pollen grains could be immediately collected. The density of pollen grains on the nylon membrane was controlled by adjusting the concentration of the pollen suspension solution. Only one DUMONT forcep was used to collect single pollen grains; adhesion of pollen grains to the forceps tip was achieved by first wetting the tip in a lysis solution. Using this protocol, pollen collection for a 96-well PCR plate could be completed within an hour.

Microsatellite markers, also known as variable number tandem repeats (VNTRs) (Jeffreys et al., 1985), simple sequence repeats (SSRs), or short tandem repeats (STRs) (Weber and May, 1989; Edwards et al., 1991), are short DNA fragments that contain varying numbers of tandem repeat units of di-, tri-, or tetra-nucleotide motifs (Edwards et al., 1991; Polymeropoulos et al., 1991). In general, size polymorphism among various SSR alleles is due to the variable number of tandem repeats they contain. Four of the five SSR primer pairs amplified alleles of different sizes (with different numbers of tandem repeats). The UGSM10 primer pair was unique in the sense that the sizes of its alleles differed by repeat units of four rather than three bases [(GGC) $)_{3}$. We speculate that either errors occurred during the primer designing process or there was an additional single base repeat unit among the amplified region. This may also have occurred with the UGSM97 primer pair. Its basic repeat unit is $(G A A)_{8}(A G)_{7}$ and in this study its alleles differed by $5(=3+2)$ bases.

Overall, 918 (95.2\%) single pollen SSR-PCR amplified products were detected on agarose gels. Forty-six (4.8\%) single pollen SSR-PCR samples did not show any SSR products (Table 3). This could be due to failure in transferring single pollen grains to the PCR tubes or to the absence of the SSR primer binding site in the DNA of the transferred pollen grain. In order to distinguish between these two, the consensus PI/PII primer pairs (Cox et al., 1992) that target the $5 S$ ribosomal RNA intergenic spacers (rRNA-ITS) were used to test the remaining SSR-PCR mixture. A negative result from the PI/PII-primed PCR confirms that no pollen grain was present in the sample, whereas a positive PI/PII-primed PCR result means that the single pollen grain has been successfully transferred but there was no specific SSR allele amplified with the primer pair. These $\mathrm{PI} / \mathrm{PII}$-positive samples were considered as null genotypes and were included in the statistical analysis. These results demonstrate the need for using at least two SSR markers when assessing cross fidelity in sugarcane, in order to reduce errors. By using the consensus housekeeping gene primer pair PI/PII, an error rate of 5\% (46 out of 964 single SSR-PCR assays) was avoided.

Under the assumptions of polysomic inheritance, absence of segregation distortion, or double reduction, simplex, duplex and triplex markers are expected to segregate in 3:1, 77:4, and $143: 1$ ratios in the $S_{1}$ population and in $1: 1,7: 2$, and $11: 1$ ratios in the pollen populations, respectively (Ripol et al., 1999; Andru et al., 2011) (Table 2). According to the segregation ratio of homopolyploids (Ripol et al., 1999) and $2 n=10$ (Andru et al., 2011), about 55\% of the SSR alleles detected in both $S_{1}$ and pollen populations segregated as single dose, double dose, or triple dose markers $\left(X^{2}=0.05\right)$. According to Ripol et al. (1999), the observed segregation ratios of markers should be equal or very close to their theoretically expected ratios for both pollen populations and 
the $S_{1}$ population. In the current study, the results were in general agreement with the theoretical segregation ratios expected from a $2 n=10 x$ polyploid.

The expected number of potential genotypes for a pair of SSR primers among pollen populations and the $S_{1}$ population was computed by $2^{n}$, where $n$ was the number of potentially amplifiable alleles. Since the numbers of observed genotypes among pollen populations were always greater than $2^{n / 2}$ for SSR primer pairs SMC1604SA, SMC336BS, SCM7, and UGSM97, it was evident that none of the SSR alleles amplified by these SSR primer pairs were closely linked. Although the UGSM10 primer pair amplified fewer than $32\left(2^{6} / 2\right)$ observed genotypes in the $S_{1}$ population, none of its six alleles seemed to be linked based on the data from the pollen populations. Assuming that the occurrence of an allele within a genotype was random, then the frequency of a genotype would be the sum of the frequency of alleles within that genotype. In the present study, highly significant correlations were found between observed frequencies of genotypes and their corresponding expected frequencies. This suggests that each of the 20 SSR alleles from the five SSR primer pairs were segregated in accordance to the Mendelian Segregation and Independent Assortment laws in both pollen populations and the $S_{1}$ population of the sugarcane cultivar LCP 85-384.

When comparing the PIC values of these SSR primer pairs between pollen and $\mathrm{S}_{1}$ populations, values from the $S_{1}$ population were always smaller or equal to those from the pollen populations, even though the $S_{1}$ population had more individuals than the pollen populations. This might be due to the fact that each individual of the $S_{1}$ population resulted from the fertilization of male and female gametes, which may share SSR alleles, thereby reducing PIC values. In theory, PIC values of zygotes are smaller than those of female or male gametes alone. Furthermore, the $\mathrm{S}_{1}$ population had always a lower number of genotypes than the pollen populations, which again could be due to sharing SSR alleles between female and male gametes. In fact, the proportion of single pollen grains sharing the same genotype of their parent LCP 85-384 tended to be lower than the proportion of individual $S_{1}$ progenies sharing the same genotype. The existence of common SSR alleles between female and male gametes resulted in relatively low PIC values for the $S_{1}$ population. This is also the reason why sugarcane breeders seldom use self progeny in breeding programs. Although more than 150 commercial cultivars have been released in the USA, only CP 00-1101 (Gilbert et al., 2008) and CP 00-2180 (Glaz et al., 2009) have been selected from $S_{1}$ populations. Nevertheless, the $S_{1}$ nature of these two clones remains questionable (Y-B Pan, personal communication).

Sugarcane breeders often prefer a cross between parental clones distantly related to each other, to minimize the risk of sharing common genes. By doing so, breeders hope to increase the genetic diversity of the breeding population and enhance the probability of selecting the ideal genotype. Results from this study also indicate that the number of potential genotypes increases geometrically when the number of alleles per SSR primer pair increases. If the population size is limited, the ratio of observed vs theoretically expected genotypes decreases dramatically. In order to observe more genotypes, population size should be increased. In sugarcane breeding, breeding success rate is largely depended on the total number of fuzz-derived seedlings. Often limited by budget, labor, and land area, sugarcane breeders have to balance the number of crosses and the number of seedlings per cross. In general, the chance of selecting a good genotype will be reduced if the seedling population size declines. Therefore, molecular marker polymorphism studies involving pollen populations may help estimate the potential genetic composition of cross progeny, determine seedling population size, and select genetically diverse parental clones. 


\section{Conflicts of interest}

The authors declare no conflict of interest.

\section{ACKNOWLEDGMENTS}

Research conducted at the USDA-ARS, MSA, Sugarcane Research Laboratory, under the USDA-ARS National Program 301 project "Genetic improvement of sugarcane by conventional and molecular approaches". This study was partially funded by the American Sugar Cane League of the U.S.A. Inc., Thibodaux, LA. The Yunnan Sugarcane Research Institute of Yunnan Academy of Agricultural Sciences and the State Administration of Foreign Experts Affairs of China Training Program covered living and travel expenses for Xin Lu and Jianrong Zhu, respectively. Guangxi Natural Science Foundation (\#2011GXNSFF018002) covered travel expenses for Hui Zhou.

\section{REFERENCES}

Aitken KS, Jackson PA and McIntyre CL (2005). A combination of AFLP and SSR markers provides extensive map coverage and identification of homo(eo)logous linkage groups in a sugarcane cultivar. Theor. Appl. Genet. 110: 789-801.

Banumathi G, Krishnasamy V, Maheswaran M, Samiyappan R, et al. (2010). Genetic diversity analysis of sugarcane (Saccharum sp.) clones using simple sequence repeat markers of sugarcane and rice. Electron. J. Plant Breed. 1: 517-526.

Cai Q, Aitken KS, Fan YH, Piperidis G, et al. (2005). A preliminary assessment of the genetic relationship between Erianthus rockii and the "Saccharum complex" using microsatellite (SSR) and AFLP markers. Plant Sci. 169: 976-984.

Chen PH, Pan YB and Chen RK. (2008). High-throughput procedure for single pollen grain collection and polymerase chain reaction in plants. J. Integr. Plant Biol. 50: 375-383.

Chen PH, Pan YB, Chen RK, Xu LP, et al. (2009). SSR marker-based analysis of genetic relatedness among sugarcane cultivars (Saccharum spp. hybrids) from breeding programs in China and other countries. Sugar Tech. 11: 347-354.

Collard BCY and Mackill DJ (2008). Marker-assisted selection: an approach for precision plant breeding in the twenty-first century. Phil. Trans. R. Soc. B. 363: 557-572.

Cordeiro GM, Taylor GO and Henry RJ (2000). Characterisation of microsatellite markers from sugarcane (Saccharum sp.), a highly polymorphic species. Plant Sci. 155: 161-168.

Cordeiro GM, Casu R, Mclntyre CL, Manners JM, et al. (2001). Microsatellite markers from sugarcane (Saccharum sp.) ESTs transferable to Erianthus and Sorghum. Plant Sci. 160: 1115-1123.

Cordeiro GM, Pan YB and Henry RJ (2003). Sugarcane microsatellites for the assessment of genetic diversity in sugarcane germplasm. Plant Sci. 165: 181-189.

Cox AV, Michael MD and Dyer TA (1992). Use of the polymerase chain reaction to detect spacer size heterogeneity in plant 5S-rRNA gene clusters and to locate such clusters in wheat (Triticum aestivum L.). Theor. Appl. Genet. 83: 684-690.

Dillon SL, Shapter FM, Henry RJ, Cordeiro G, Izquierdo L, Slade Lee L (2007). Domestication to crop improvement: genetic resources for Sorghum and Saccharum (Andropogoneae). Ann. Bot. 100: 975-989.

Edme SJ, Glynn NG and Comstock JC (2006). Genetic segregation of microsatellite markers in Saccharum officinarum and S. spontaneum. Heredity 97: 366-375.

Edwards A, Civitello A, Hammond HA and Caskey CT (1991). DNA typing and genetic mapping with trimeric and tetrameric tandem repeats. Am. J. Hum. Genet. 49: 746-756.

Gilbert RA, Comstock JC, Glaz B, Edmé SJ, et al. (2008). Registration of 'CP 00-1101' sugarcane. J. Plant Regist. 2: 95-101.

Glaz B, Edme SJ, Davidson RW, Gilbert RA, et al. (2009). Registration of 'CP 00-2180' sugarcane. J. Plant Regist. 3: 35-41.

Jeffreys AJ, Wilsom $V$ and Thein SL (1985). Hypervariable minisatellite regions in human DNA. Nature 314: 67-73.

Liu PW, Que YX and Pan YB (2011). Highly polymorphic microsatellite DNA markers for sugarcane germplasm evaluation and variety identity testing. Sugar Tech. 13: 129-136.

Milbourne D, Meyer R, Bradshaw JE, Baird E, et al. (1997). Comparison of PCR-based marker systems for the analysis of genetic relationships in cultivated potato. Mol. Breed. 3: 127-136.

Milligan SB, Martin FA, Bischoff KP, Quebedeaux JP, et al. (1994). Registration of 'LCP 85-384' sugarcane. Crop Sci. 34: 819-820.

Pan YB (2006). Highly polymorphic microsatellite DNA markers for sugarcane germplasm evaluation and variety identity 
testing. Sugar Tech. 8: 246-256.

Pan YB (2010). Databasing molecular identities of sugarcane (Saccharum spp.) clones constructed with microsatellite (SSR) DNA markers. Am. J. Plant Sci. 1: 87-94.

Pan YB, Burner DM and Legendre BL (2000). An assessment of the phylogenetic relationship among sugarcane and related taxa based on the nucleotide sequence of the 5S rRNA intergenic spacers. Genetica 108: 285-295.

Pan YB, Cordeiro GM, Richard EP and Henry J (2003). Molecular genotyping of sugarcane clones with microsatellite DNA markers. Maydica 48: 319-329.

Pan YB, Scheffler BE and Richard EP (2007). High throughput genotyping of commercial sugarcane clones with microsatellite (SSR) DNA markers. Sugar Tech. 9: 176-181.

Parida SK, Kalia SK, Kaul S, Dalal V, et al. (2009). Informative genomic microsatellite markers for efficient genotyping applications in sugarcane. Theor. Appl. Genet. 118: 327-338.

Polymeropoulos MH, Xiao H, Rath DS and Merril CR (1991). Tetranucleotide repeat polymorphism at the human tyrosine hydroxylase Gene (TH). Nucleic Acids Res. 19: 3753.

Ripol MI, Churchill GA, Silva JAG and Sorrells M (1999). Statistical aspects of genetic mapping in autopolyploids. Gene 235: 31-41.

Singh RK, Srivastava S, Singh SP, Sharma ML, et al. (2008). Identification of new microsatellite DNA markers for sugar and related traits in sugarcane. Sugar Tech. 10: 327-333.

Singh RK, Mishra SK, Singh SP, Mishra N, et al. (2010). Evaluation of microsatellite markers for genetic diversity analysis among sugarcane species and commercial hybrids. Aust. J. Crop Sci. 4: 115-124.

Suman A, Pan YB, Thongthawee S, Burner DM, et al. (2011). Genetic analysis of the sugarcane (Saccharum spp.) cultivar 'LCP 85-384'. I. Linkage mapping using AFLP, SSR, and TRAP markers. Theor. Appl. Genet. 123: 77-93.

Tew TL and Pan YB (2005). Molecular assessment of the fidelity of sugarcane crosses with high-throughput microsatellite genotyping. J. Am. Soc. Sugar Cane Technol. 25: 119.

Tew TL and Pan YB (2010). Microsatellite (simple sequence repeat) marker-based paternity analysis of a seven-parent sugarcane polycross. Crop Sci. 50: 1401-1408.

Ukoskit K, Thipmongkolcharoen P and Chatwachirawong P (2012). Novel expressed sequence tag-simple sequence repeats (EST-SSR) markers characterized by new bioinformatic criteria reveal high genetic similarity in sugarcane (Saccharum spp.) breeding lines. Afr. J. Biotechnol. 11: 1337-1363.

Weber JL and May PE (1989). Abundant class of human DNA polymorphisms which can be typed using the polymerase chain reaction. Am. J. Hum. Genet. 44: 388-396. 